\title{
Risk factors for blood transfusion in adolescent patients with scoliosis undergoing scoliosis surgery: a study of 722 cases in a single center
}

Yulei Dong, Ning Tang, Shengru Wang, Jianguo Zhang and Hong Zhao (D)

\begin{abstract}
Background: To assess the risk factors for blood transfusion in a great number of adolescent cases with different types of scoliosis who received scoliosis surgery.

Methods: Data of patients who were diagnosed as scoliosis and received one-stage posterior correction and spinal fusion from January 2014 to December 2017 were prospectively collected and retrospectively analyzed. Patients' demographic characteristics, segments of spinal fusion, Cobb angle of the major curve,osteotomy pattern, preoperative and postoperative levels of hemoglobin, and allogeneic blood transfusion (ABT) were recorded and analyzed.
\end{abstract}

Results: In this study, 722 cases with adolescent scoliosis were included, of whom 32.8\% (237/722) received ABT. Risk factors included diagnosis: neurofibromatosis $(O R=5.592)$, syndromic $(O R=3.029)$,osteotomy: Ponte osteotomy $(O R=5.997)$, hemivertebrae resection $(O R=29.171)$, pedicle subtraction osteotomy $(P S O)(O R=8.712)$, vertebral column resection (VCR) $(\mathrm{OR}=32.265)$; fusion segments $(\mathrm{OR}=1.224)$ and intraoperative blood loss $(\mathrm{OR}=1.004)$. In the subgroup analysis of cases with idiopathic scoliosis, Ponte osteotomy ( $O R=6.086)$, length of segments of spinal fusion ( $O R=1.293)$, and intraoperative blood loss $(O R=1.001)$ were found as risk factors for ABT. Results of receiver operating characteristic (ROC) curve analysis revealed that length of segments of spinal fusion equal to 11.5 vertebrae was the best cutoff value for cases with idiopathic scoliosis who did not receive osteotomy in both ABT group and non-ABT group. In the subgroup analysis of congenital scoliosis, Ponte osteotomy $(O R=5.087)$, hemivertebra resection $(O R=5.457)$, PSO $(O R=4.055), V C R(O R=6.940)$, and intraoperative blood loss $(O R=1.004)$ were risk factors for $\mathrm{ABT}$.

Conclusions: Method of diagnosis, osteotomy pattern, segments of spinal fusion, and intraoperative blood loss were risk factors for ABT in cases with adolescent scoliosis. In cases with idiopathic scoliosis, Ponte osteotomy and segments of spinal fusion longer than 11.5 vertebrae were risk factors for ABT. In cases with congenital scoliosis, osteotomy pattern was the main risk factor for ABT.

Level of evidence: Level III.

Keywords: Scoliosis, Spine fusion, Blood transfusion, Osteotomy

\footnotetext{
* Correspondence: zhaohongyisheng@126.com

Department of Orthopedic Surgery, Peking Union Medical College Hospital, Chinese Academy of Medical Science and Peking Union Medical College, Beijing 100730, China
}

(c) The Author(s). 2021 Open Access This article is licensed under a Creative Commons Attribution 4.0 International License, which permits use, sharing, adaptation, distribution and reproduction in any medium or format, as long as you give appropriate credit to the original author(s) and the source, provide a link to the Creative Commons licence, and indicate if changes were made. The images or other third party material in this article are included in the article's Creative Commons licence, unless indicated otherwise in a credit line to the material. If material is not included in the article's Creative Commons licence and your intended use is not permitted by statutory regulation or exceeds the permitted use, you will need to obtain permission directly from the copyright holder. To view a copy of this licence, visit http://creativecommons.org/licenses/by/4.0/ The Creative Commons Public Domain Dedication waiver (http://creativecommons.org/publicdomain/zero/1.0/) applies to the data made available in this article, unless otherwise stated in a credit line to the data. 


\section{Background}

Scoliosis surgery is one of the most challenging surgeries in orthopedics. The surgery often requires extensive soft tissue exposure and bone resection that may cause a significant risk of blood transfusion [1]. Allogeneic blood transfusion $(\mathrm{ABT})$ is associated with an increased risk of surgical site and systemic infection, transmission of infectious agents, acute hemolytic reactions, and transfusion-related immunomodulation [2]. Moreover, both autologous and allogeneic transfusions contribute to longer duration of hospitalization and, consequently, increased hospital costs [3]. Blood conservation techniques, such as tranexamic acid, intraoperative cell salvage, and controlled hypotension during operation reduce the risk of $\mathrm{ABT}$ [4]. However, long segments of spinal fusion and osteotomy still cause a large amount of blood loss and necessitate blood transfusion. Studies have reported predictive factors for blood transfusion in scoliosis surgery; however, the majority of cases had idiopathic scoliosis [5-7]. The association between etiology of scoliosis and blood transfusion was scarcely reported. Congenital scoliosis often requires osteotomy, causing more blood loss than idiopathic scoliosis. A systemic analysis of scoliosis surgery and blood transfusion with respect to blood conservation in modern surgery is highly essential for clinical decision making. The present study aimed to evaluate the risk factors for blood transfusion in a great number of cases with different types of scoliosis who received scoliosis surgery.

\section{Methods}

\section{Patients}

Patients who were diagnosed as scoliosis and received one-stage posterior correction and posterior spinal fusion from January 2014 to December 2017 were included in the current study. The patients' age was 10-18 years old. Besides, cases diagnosed as degenerative scoliosis, and those who underwent revision surgery, had preoperative anemia or coagulation disorders were excluded. The patients' demographic characteristics and clinical data, such as preoperative and postoperative hemoglobin, blood transfusion, segments of spinal fusion, osteotomy pattern, Cobb angle of the major curve and correction rate were collected and analyzed.

\section{Surgical procedures}

All the surgeries were performed by senior surgeons in our medical center that is one of the most well-known spinal deformity centers in China. A midline posterior approach was applied and paravertebral muscles were detached by electrocautery. Pedicle screws were inserted by using free-hand technique. Ponte osteotomy, hemivertebra resection, pedicle subtraction osteotomy (PSO) or vertebral column resection (VCR) was performed for severe and rigid scoliosis according to surgeons' experience. The osteotomy was performed by traditional osteotome. Bone wax was applied during surgery for bleeding from cancellous bone. Fusion was obtained by decortication with autologous spinal process or allograft cancellous bone. For all the patients, a drainage tube was placed under the fascia and removed $48-72 \mathrm{~h}$ after the surgery. Intraoperative blood loss included the amount of blood in suction container and surgical sponges.

\section{Blood transfusion strategy}

Tranexamic acid was infused at a loading dose of $1 \mathrm{~g}$ before the surgery with a maintenance dose of $10 \mathrm{mg} /$ $\mathrm{kg} / \mathrm{h}$ until the wound closure. Ringer's lactate solution and hydroxyethyl starch solution were used for hemodilution after general anesthesia and before the surgery. Controlled hypotension with a mean arterial pressure (MAP) of $80 \mathrm{mmHg}$ was maintained during the surgery. A cell saver was utilized intraoperatively in all the patients. Bipolar electrocautery was applied in all the cases. Intraoperative blood gas analysis was applied for patients with large amount of blood loss. Blood test was carried out at each morning 3 days after the surgery and before being discharged from hospital. If the hemoglobin level was lower than $70 \mathrm{~g} /$ $\mathrm{L}$, allogeneic red blood cells were infused. If the hemoglobin level was $70-100 \mathrm{~g} / \mathrm{L}$, allogeneic red blood cells were infused when a significant symptom of anemia was observed, such as lower blood pressure and increased heart rate. Blood transfusion did not include transfusion of fresh frozen plasma, platelets, cryoprecipitate, or albumin. All the patients received erythropoietin (EPO; 10,000 Units/day) and intravenous iron sucrose $(100-200 \mathrm{mg} /$ day $)$ for 3-5 days postoperatively.

\section{Statistical analysis}

Statistical analysis was performed using SPSS 16.0 software (IBM, Armonk, NY, USA). All continuous variables were expressed as a mean \pm standard deviation. The independent $\mathrm{t}$-test was employed to compare the differences between the ABT group and non-ABT group. Categorical variables were compared using the Pearson Chi-square test. Independent factors related to the transfusion were identified by binary logistic regression analysis. $P<0.05$ was considered statistically significant.

\section{Results}

In the present study, 722 cases with adolescent scoliosis were included, of whom $32.8 \%$ (237/722) received ABT. The results of univariate analysis are shown in Table 1. The patients' mean age in ABT group was slightly younger than that in non-ABT group, and there were more male patients in the ABT group. For 
Table 1 Univariate analysis between allogeneic blood transfusion group and non-transfusion group

\begin{tabular}{|c|c|c|c|c|}
\hline & Non-Transfusion group & Transfusion group & Transfusion rate & $P$ \\
\hline Age (year) & $14.4 \pm 1.8$ & $14.0 \pm 2.0$ & & 0.013 \\
\hline BMI $(\mathrm{kg} / \mathrm{m} 2))$ & $19.0 \pm 3.4$ & $18.5 \pm 3.7$ & & 0.205 \\
\hline Gender, male/total (\%) & $128 / 485(26.4 \%)$ & 85/237 (35.9\%) & & 0.009 \\
\hline Diagnosis, n(\%) & 485 (100\%) & 237 (100\%) & & 0.000 \\
\hline Idiopathic, n(\%) & $308(63.5 \%)$ & $64(27 \%)$ & $17.2 \%$ & \\
\hline Congenital, n(\%) & $116(23.9 \%)$ & $108(45.5 \%)$ & $48.2 \%$ & \\
\hline Neurofibromatosis, n(\%) & $11(2.3 \%)$ & $17(7.2 \%)$ & $60.7 \%$ & \\
\hline Syndromic, n(\%) & $21(4.3 \%)$ & $35(14.8 \%)$ & $62.5 \%$ & \\
\hline Neuromuscular, n(\%) & $29(6.0 \%)$ & $13(5.5 \%)$ & $31.0 \%$ & \\
\hline Osteotomy pattern, n(\%) & $485(100 \%)$ & $237(100 \%)$ & & 0.000 \\
\hline Fusion without osteotomy, n(\%) & 443 (91.3\%) & $152(64.1 \%)$ & $25.5 \%$ & \\
\hline Ponte osteotomy, n(\%) & $12(2.5 \%)$ & $18(7.6 \%)$ & $60 \%$ & \\
\hline Hemivertebrae resection, n(\%) & $19(3.9 \%)$ & $39(16.5 \%)$ & $67.2 \%$ & \\
\hline PSO, n(\%) & $9(1.9 \%)$ & $15(6.3 \%)$ & $62.5 \%$ & \\
\hline VCR, n(\%) & $2(0.4 \%)$ & $13(5.5 \%)$ & $86.7 \%$ & \\
\hline Cobb angle of major curve-preoperative, degree & $53.5 \pm 10.6$ & $57.5 \pm 11.5$ & & 0.108 \\
\hline Cobb angle of major curve-postoperative, degree & $18.5 \pm 9.0$ & $16.5 \pm 8.5$ & & 0.309 \\
\hline Major curve correction rate, $\%$ & $62 \pm 7.6$ & $59.5 \pm 6.4$ & & 0.205 \\
\hline Fusion segments & $9.8 \pm 2.7$ & $11.6 \pm 3.4$ & & 0.000 \\
\hline Preoperative HGB, g/L & $136.2 \pm 11.7$ & $135.3 \pm 14.0$ & & 0.356 \\
\hline Intraoperative Blood loss, mL & $414.5 \pm 235.6$ & $839.4 \pm 573.7$ & & 0.000 \\
\hline Intraoperative cell salvage, mL & $200.9 \pm 166.8$ & $397.6 \pm 323.7$ & & 0.000 \\
\hline HGB POD1, g/L & $108.2 \pm 15.0$ & $111.1 \pm 16.0$ & & 0.018 \\
\hline HGB POD3, g/L & $102.7 \pm 14.1$ & $105.4 \pm 14.9$ & & 0.041 \\
\hline HGB POD5, g/L & $103.2 \pm 13.9$ & $105.8 \pm 15.2$ & & 0.273 \\
\hline
\end{tabular}

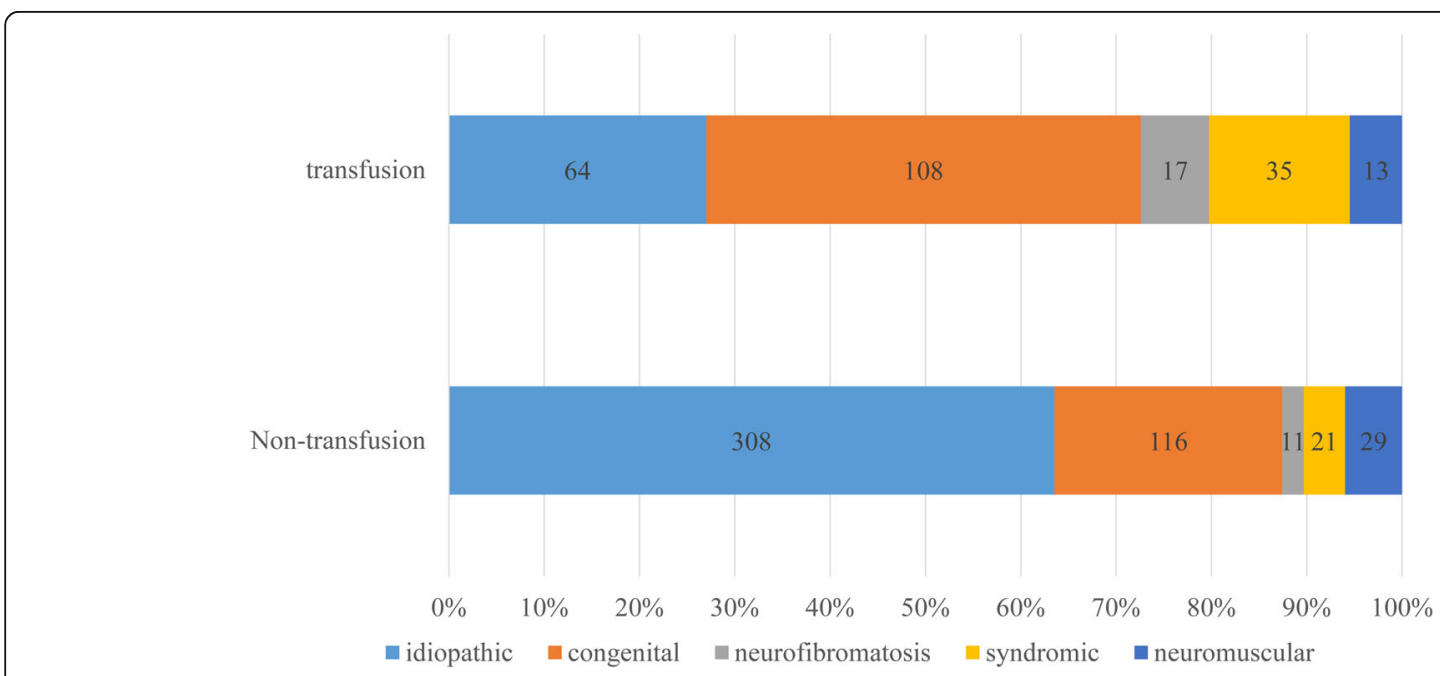

Fig. 1 The relationship between blood transfusion rate and method of diagnosis. There were more cases with congenital scoliosis in ABT group compared to non-ABT group, while there was a greater proportion of cases with idiopathic scoliosis in non-ABT group than that in ABT group 


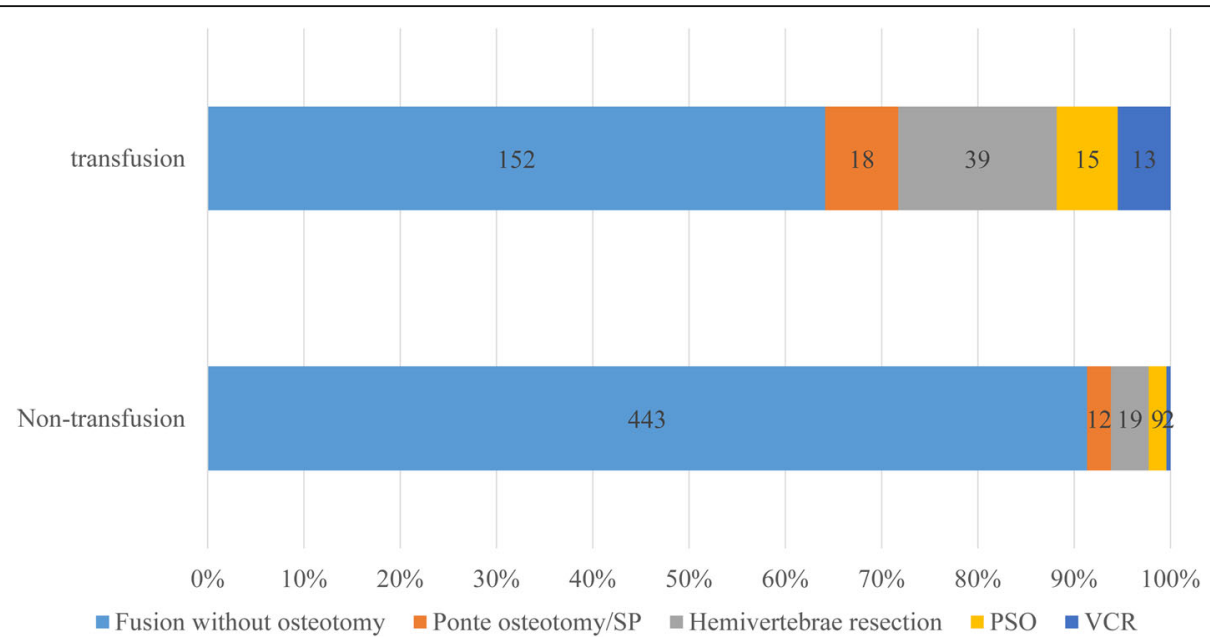

Fig. 2 The relationship between blood transfusion rate and osteotomy pattern. There were a larger proportion of cases who received osteotomy in ABT group compared to non-ABT group

classification of the etiology, the rate of diagnosis was different in the non-ABT group and ABT group. There were more cases with idiopathic scoliosis in non-ABT group compared to ABT group $(63.5 \%$ vs. $27 \%$ ), and more cases with congenital scoliosis in the transfusion group compared to non-ABT group (45.5\% vs. $23.9 \%)$ (Fig. 1). The osteotomy pattern was also different in non-ABT group and ABT group. Additionally, $8.7 \%$ of cases in the non-ABT group underwent osteotomy, while $35.9 \%$ of cases in the ABT group received osteotomy (Fig. 2). The Cobb angle of the major curve was comparable between the two groups $(53.5 \pm 10.6$ vs. $57.5 \pm 11.5)$. The length of segments of spinal fusion was markedly shorter in non-ABT group compared with that in ABT group $(9.8 \pm 2.7$ vs. $11.6 \pm 3.4, P=0.000)$. The average blood loss and autologous blood transfusion were significantly decreased in the non-ABT group. The hemoglobin level was slightly lower at the postoperative day 1 (POD1) and POD3, while it became comparable at POD5.

The results of analysis of risk factors are summarized in Table 2. The diagnosis, methods of osteotomy, segments of spinal fusion, and intraoperative blood loss were the most significant risk factors. Patients with neurofibromatosis scoliosis (odds ratio $(\mathrm{OR})=5.592, P=$ $0.001)$ and syndromic scoliosis $(\mathrm{OR}=3.029, P=0.004)$ had a significantly higher incidence of ABT. Ponte osteotomy $(\mathrm{OR}=5.997, P=0.000)$, hemivertebra resection $(\mathrm{OR}=29.171, P=0.000)$, $\mathrm{PSO}(\mathrm{OR}=8.712, P=0.018)$, and VCR $(\mathrm{OR}=32.265, P=0.002)$ showed a significantly higher incidence of $\mathrm{ABT}$ in patients who received osteotomy compared with those who did not. Segments of spinal fusion $(\mathrm{OR}=1.224, P=0.000)$ and intraoperative blood loss $(\mathrm{OR}=1.004, P=0.000)$ were also found as independent risk factors for ABT.

The results of subgroup analysis of cases with idiopathic scoliosis are shown in Table 3. The transfusion rate in cases with idiopathic scoliosis was $17.2 \%$ (64/ 372 ). In addition, the proportion of cases that underwent Ponte osteotomy was notably higher in $\mathrm{ABT}$

Table 2 Multivariate analysis of independent risk factors associated with allogeneic blood transfusion

\begin{tabular}{|c|c|c|c|}
\hline factors & Odds ratio & $95 \% \mathrm{Cl}$ & $P$ \\
\hline Diagnosis & & & 0.001 \\
\hline Idiopathic & 1 & 1 & \\
\hline Congenital & 1.716 & $0.985-2.991$ & 0.057 \\
\hline Neurofibromatosis & 5.592 & $2.065-15.144$ & 0.001 \\
\hline Syndromic & 3.029 & $1.434-6.396$ & 0.004 \\
\hline Neuromuscular & 1.048 & $0.418-2.629$ & 0.920 \\
\hline Osteotomy & & & 0.000 \\
\hline Fusion without osteotomy & 1 & 1 & \\
\hline Ponte osteotomy & 5.997 & $2.266-15.872$ & 0.000 \\
\hline Hemivertebrae resection & 29.171 & $9.491-89.658$ & 0.000 \\
\hline PSO & 8.712 & $1.449-52.368$ & 0.018 \\
\hline VCR & 32.265 & $3.673-283.462$ & 0.002 \\
\hline \multicolumn{4}{|l|}{ Gender } \\
\hline Male & 1 & 1 & \\
\hline Female & 1.474 & $0.873-2.489$ & 0.147 \\
\hline Age & 0.881 & $0.781-0.994$ & 0.040 \\
\hline Fusion segments & 1.224 & $1.115-1.345$ & 0.000 \\
\hline Intraoperative Blood loss & 1.004 & $1.002-1.005$ & 0.000 \\
\hline Intraoperative cell salvage & 0.998 & $0.997-1.000$ & 0.097 \\
\hline
\end{tabular}


Table 3 Univariate analysis between allogeneic blood transfusion group and non-transfusion group in idiopathic scoliosis

\begin{tabular}{|c|c|c|c|}
\hline & Non-transfusion group & Transfusion group & $P$ \\
\hline Age (year) & $14.7 \pm 1.7$ & $14.7 \pm 1.8$ & 0.803 \\
\hline BMI $(\mathrm{kg} / \mathrm{m} 2))$ & $18.8 \pm 3.1$ & $18.9 \pm 3.9$ & 0.928 \\
\hline Gender, male/total (\%) & $54 / 308$ & $15 / 64$ & 0.269 \\
\hline Osteotomy pattern, n(\%) & $308(100 \%)$ & $64(100 \%)$ & 0.000 \\
\hline Fusion without osteotomy, n(\%) & $304(98.7 \%)$ & $57(89.1 \%)$ & \\
\hline Ponte osteotomy, n(\%) & $4(1.3 \%)$ & $7(10.9 \%)$ & \\
\hline Cobb angle of major curve-preoperative, degree & $57.5 \pm 11.5$ & $59.5 \pm 12.5$ & 0.068 \\
\hline Cobb angle of major curve-postoperative, degree & $13.5 \pm 6.0$ & $12.5 \pm 5.5$ & 0.189 \\
\hline Major curve correction rate, $\%$ & $72.0 \pm 9.5$ & $74.5 \pm 8.4$ & 0.091 \\
\hline Fusion segments & $9.6 \pm 2.7$ & $12.1 \pm 2.6$ & 0.000 \\
\hline Preoperative HGB, g/L & $134.9 \pm 11.7$ & $133.3 \pm 17.1$ & 0.366 \\
\hline Intraoperative Blood loss, mL & $400.2 \pm 243.9$ & $713.6 \pm 394.1$ & 0.000 \\
\hline Intraoperative cell salvage, $\mathrm{mL}$ & $190.7 \pm 165.8$ & $358.6 \pm 246.6$ & 0.000 \\
\hline HGB POD1, g/L & $107.6 \pm 14.4$ & $109.2 \pm 19.3$ & 0.452 \\
\hline HGB POD3, g/L & $102.3 \pm 13.7$ & $104.6 \pm 15.2$ & 0.335 \\
\hline HGB POD5, g/L & $102.4 \pm 15.1$ & $107.5 \pm 11.8$ & 0.268 \\
\hline
\end{tabular}

group compared with that in non-ABT group $(10.9 \%$ vs. $1.3 \%, P=0.000)$. The major curve correction rate was a little higher in the ABT group $(72.0 \pm 9.5$ vs.74.5 \pm 8.4 ), however, it didn't reach statistical significance. The length of segments of spinal fusion was significantly shorter in non-ABT group than that in ABT group $(9.6 \pm 2.7$ vs. $12.1 \pm 2.6, P=0.000)$. Results of multivariate regression analysis indicated that Ponte osteotomy $(\mathrm{OR}=6.086, P=0.000)$ and segments of spinal fusion $(\mathrm{OR}=1.293, P=0.000)$ were independent risk factors for ABT. Receiver operating characteristic (ROC) curve analysis revealed that 11.5 was the best cutoff segment for idiopathic scoliosis cases without undergoing osteotomy in ABT and non-ABT groups (Fig. 3; sensitivity, 72.1\%; specificity, 64.5\%) (Table 4).

The results of subgroup analysis of congenital scoliosis are presented in Table 5. The transfusion rate of congenital scoliosis was $48.2 \%(108 / 224)$. The proportion of cases that received osteotomy was remarkably higher in ABT group compared with that in non-ABT group (62\% vs. $29.3 \%, P=0.000$ ). The segments of spinal fusion and were comparable between the two groups (ABT group $(10.3 \pm 2.7)$ vs. non-ABT group $(10.6 \pm 4.1, P=0.518)$ ). The Cobb angle of major curve and the correction rate were also comparable in the two groups. Multivariate regression analysis results of independent risk factors of congenital scoliosis are summarized in Table 6. Ponte osteotomy $(\mathrm{OR}=5.087, \quad P=0.025), \quad$ hemivertebra resection ( $\mathrm{OR}=5.457, P=0.000)$, $\mathrm{PSO}(\mathrm{OR}=4.055, P=$ $0.015)$, and VCR $(\mathrm{OR}=6.940, P=0.024)$ were all associated with high risk of blood transfusion.

\section{Discussion}

Scoliosis surgery aims to reduce the abnormal curve in the spine and prevent it from getting worse. Several studies have reported the risk factors for massive blood transfusion in patients with adolescent scoliosis $[1,4-8]$. The results of the current study showed that $32.8 \%$

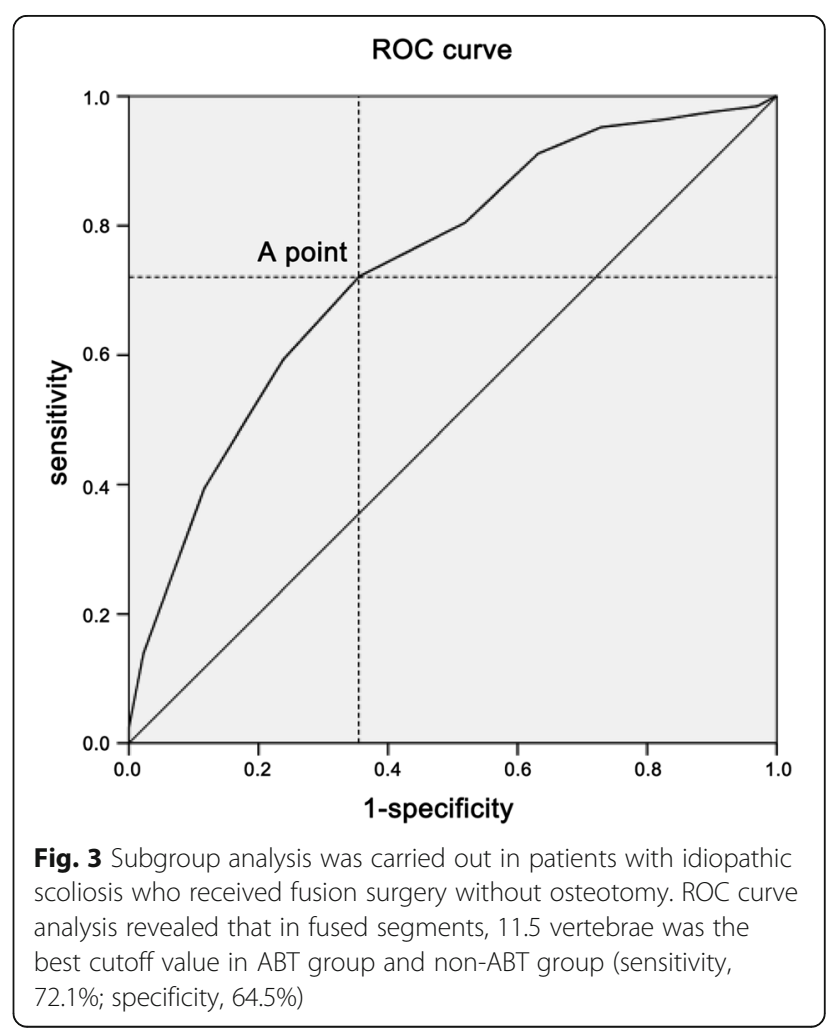


Table 4 Multivariate analysis of independent risk factors associated with allogeneic blood transfusion in idiopathic scoliosis

\begin{tabular}{llll}
\hline Factors & Odds ratio & $\mathbf{9 5 \% C l}$ & $\boldsymbol{P}$ \\
\hline Osteotomy & & & 0.000 \\
Fusion without osteotomy & 1 & 1 & \\
Ponte osteotomy & 6.086 & $3.894-9.513$ & 0.000 \\
Fusion segments & 1.293 & $1.232-1.357$ & 0.000 \\
Intraoperative Blood loss & 1.001 & $1.001-1.002$ & 0.000 \\
Intraoperative cell salvage & 1.000 & $1.000-1.001$ & 0.188 \\
\hline
\end{tabular}

(237/722) of patients with different types of scoliosis received ABT. Thus, it is of great significance to be aware of the characteristics of blood transfusion preoperatively for clinical decision making.

According to the literature, the transfusion rate in cases with idiopathic scoliosis ranged from 1.7 to $67.6 \%$ $[8,9]$. Hassan et al. studied 110 patients with scoliosis, and it was demonstrated that the transfusion rate was only $1.7 \%(1 / 60)$ for cases with idiopathic scoliosis. In that research, patients received preoperative evaluation, cell salvage, topical hemostasis, antifibrinolytics, and hypotensive anesthesia. Their results indicated that implementation of a blood management protocol resulted in a low transfusion rate and unexpectedly led to the preoperative diagnosis in a number of patients with a low level of von Willebrand factor activity [9]. In a recently conducted research, $\mathrm{ABT}$ was noted in 73 (18.2\%) out of 402 patients with idiopathic scoliosis [7], which is quite similar to the findings of the present study. In our research, the blood transfusion rate in cases with idiopathic scoliosis was 17.2\% (64/372). Our findings were almost the same except for two surgical strategies, which might lead to a faster surgery, reduced intraoperative blood loss, and a reduced risk of ABT [10, 11 .

Longer segments of spinal fusion were noted to be associated with a higher risk of ABT. In the present study, we found that segments of spinal fusion longer than 11.5 vertebrae had the best cutoff value in $\mathrm{ABT}$ group and non-ABT group. A similar conclusion was drawn from a National Surgical Quality Improvement Program pediatric database from 2012 to 2013. They concluded that posterior arthrodesis of 13 or more vertebral segments $(P<0.001)$ were independent risk factors for requiring blood transfusion in AIS patients [8]. This conclusion was quite useful before surgery which implies selective thoracic or lumbar fusion have very low incidence of blood transfusion.

Congenital scoliosis is a failure of vertebral formation and/or segmentation arising from abnormal vertebral development during gestation. Neuromuscular scoliosis (NMS) refers to a non-congenital spinal deformity that occurs in patients with any type of pre-existing neuromuscular diagnosis. NMS may affect patients of any age,

Table 5 Univariate analysis between allogeneic blood transfusion group and non-transfusion group in congenital scoliosis

\begin{tabular}{|c|c|c|c|}
\hline & Non-transfusion group & Transfusion group & $P$ \\
\hline Age (year) & $13.7 \pm 1.8$ & $13.7 \pm 2.0$ & 0.894 \\
\hline BMI $(\mathrm{kg} / \mathrm{m} 2))$ & $19.2 \pm 3.7$ & $19.1 \pm 3.9$ & 0.865 \\
\hline Gender, male/total (\%) & $46 / 116(39.7 \%)$ & $43 / 108(39.8 \%)$ & 0.981 \\
\hline Osteotomy pattern, n(\%) & $116(100 \%)$ & $108(100 \%)$ & 0.000 \\
\hline Fusion without osteotomy, n(\%) & $82(70.7 \%)$ & $41(38.0 \%)$ & \\
\hline Ponte osteotomy, n(\%) & $4(3.4 \%)$ & $6(5.6 \%)$ & \\
\hline Hemivertebrae resection, n(\%) & 19 (16.4\%) & $39(36.1 \%)$ & \\
\hline PSO, n(\%) & $9(7.8 \%)$ & $13(12.0 \%)$ & \\
\hline$V C R, n(\%)$ & $2(1.7 \%)$ & $9(8.3 \%)$ & \\
\hline Cobb angle of major curve-preoperative, degree & $60.5 \pm 9.5$ & $61.3 \pm 8.8$ & 0.338 \\
\hline Cobb angle of major curve-postoperative, degree & $23.5 \pm 7.5$ & $25.5 \pm 8.4$ & 0.209 \\
\hline Major curve correction rate, $\%$ & $58.4 \pm 10.5$ & $59.3 \pm 9.4$ & 0.101 \\
\hline Fusion segments & $10.3 \pm 2.7$ & $10.6 \pm 4.1$ & 0.518 \\
\hline Preoperative HGB, g/L & $137.7 \pm 10.3$ & $136.6 \pm 12.6$ & 0.444 \\
\hline Intraoperative Blood loss, mL & $425.8 \pm 229.4$ & $843.7 \pm 678.9$ & 0.000 \\
\hline Intraoperative cell salvage, $\mathrm{mL}$ & $204.7 \pm 168.6$ & $398.7 \pm 361.9$ & 0.000 \\
\hline HGB POD1, g/L & $109.3 \pm 15.4$ & $113.6 \pm 15.1$ & 0.039 \\
\hline HGB POD3, g/L & $102.5 \pm 15.2$ & $108.4 \pm 14.9$ & 0.016 \\
\hline HGB POD5, g/L & $103.1 \pm 13.3$ & $109.7 \pm 17.0$ & 0.158 \\
\hline
\end{tabular}


Table 6 Multivariate analysis of independent risk factors associated with allogeneic blood transfusion in congenital scoliosis

\begin{tabular}{llll}
\hline factors & Odds ratio & $\mathbf{9 5 \% C l}$ & $\boldsymbol{P}$ \\
\hline Osteotomy & & & 0.000 \\
Fusion without osteotomy & 1 & 1 & \\
Ponte osteotomy & 5.087 & $1.224-21.139$ & 0.025 \\
Hemivertebrae resection & 5.457 & $2.462-12.095$ & 0.000 \\
PSO & 4.055 & $1.314-12.517$ & 0.015 \\
VCR & 6.940 & $1.284-37.496$ & 0.024 \\
Intraoperative blood loss & 1.004 & $1.002-1.006$ & 0.000 \\
Intraoperative cell salvage & 1.000 & $0.997-1.003$ & 0.977 \\
\hline
\end{tabular}

and progress relentlessly in many cases, particularly in patients with more severe neurologic and systemic involvement. Hassan et al. studied 28 cases with NMS, of whom $36 \%$ required $\mathrm{ABT}$, which is quite similar to the rate achieved in the current research (13/42, 31\%) [9]. Claire et al. investigated 147 patients with scoliosis, and found that incidence of congenital scoliosis and NMS was 21.4 and $76.5 \%$, respectively. Their results indicated that the blood transfusion rate was only $9.4 \%$ in patients with idiopathic scoliosis, which was notably lower than that in cases with congenital scoliosis and NMS [12]. Yu et al. assessed predictors of massive blood loss after scoliosis surgery, and it was concluded that the risk of massive blood loss in patients with scoliosis could increase if they had preoperative Cobb angle $>50^{\circ}$ or aimed to undergo osteotomy or fusion of more than 6 levels [13]. To our knowledge, the number of levels to be fused is a good predictor of massive blood loss in scoliosis surgery. In our research, the Cobb angle of the major curve was comparable between ABT and nonABT group. We defined the osteotomy pattern for each case, and it seems to be more important than Cobb angle. The analysis of independent risk factors showed that diagnosis of neurofibromatosis was associated with a high OR of 5.592 compared to idiopathic scoliosis. This could be explained by malformation of pedicle in neurofibromatosis scoliosis, which may cause failure in pedicle screw fixation, thereby increasing the exposure time $[14,15]$.

Osteotomy often causes a large amount of blood loss. In the present research, the transfusion rate in cases who underwent osteotomy varied between 60 and 86.7\%. For congenital scoliosis, the main risk factor for blood transfusion is osteotomy with an OR value greater than 4. Chang et al. estimated that the blood loss of VCR was $1916 \mathrm{ml}$ [16]. To reduce the incidence of transfusion in cases with a high level of osteotomy, further effective approaches are required, and blood conservation protocols remain to be updated.
The advantage of our study is the large case sample which is quite essential to determine the true value of transfusion rate. All patients received consistent blood saving scheme. Subgroup analysis was carried out between different diagnosis and surgical methods, which is useful in surgery decision making process. However, there are several shortcomings in the current study. Firstly, duration of surgery were not measured for each case separately. Secondly, its retrospective nature is one of the main limitations.

\section{Conclusions}

In summary, method of diagnosis, osteotomy pattern, segments of spinal fusion, and intraoperative blood loss were found as risk factors for blood transfusion in cases with adolescent scoliosis. In cases with idiopathic scoliosis, Ponte osteotomy and segments of spinal fusion longer than 11.5 vertebrae were risk factors for ABT. In cases with congenital scoliosis, osteotomy pattern was the main risk factor for ABT.

\section{Abbreviations}

PSO: Pedicle subtraction osteotomy; MAP: Mean arterial pressure; POD: Postoperative day; VCR: Vertebral column resection

\section{Acknowledgements}

We thank Miss Shanshan Wang and Ying Ding for their help with the statistics.

\section{Authors' contributions \\ DYL performed measurements and manuscript preparation; TN performed measurements and manuscript preparation; WSR performed statistical analysis and manuscript preparation; ZJG performed study design and surgeries; ZH performed study design and surgeries. The author(s) read and} approved the final manuscript.

\section{Funding}

NA

Availability of data and materials

Please contact the corresponding author for scientific use.

Ethics approval and consent to participate

This retrospective study without intervention was approved by Peking Union Medical College Hospital Ethical Committee. A written informed consent was obtained from a parent or guardian for participants under 16 years old when admitted into ward about medical records for scientific use.

Consent for publication

Not Applicable.

Competing interests

NA

Received: 31 July 2020 Accepted: 9 December 2020

Published online: 05 January 2021

\section{References}

1. Koerner JD, Patel A, Zhao C, et al. Blood loss during posterior spinal fusion for adolescent idiopathic scoliosis. Spine (Phila Pa 1976). 2014;39(18): 1479-87.

2. Ponnusamy KE, Kim TJ, Khanuja HS. Perioperative blood transfusions in orthopaedic surgery. J Bone Joint Surg Am. 2014;96(21):1836. 
3. Seicean A, Alan N, Seicean S, et al. The effect of blood transfusion on shortterm, perioperative outcomes in elective spine surgery. J Clin Neurosci. 2014;21(9):1579-85.

4. Ohrt-Nissen S, Bukhari N, Dragsted C, et al. Blood transfusion in the surgical treatment of adolescent idiopathic scoliosis-a single-center experience of patient blood management in 210 cases. Transfusion. 2017;57(7):1808-17.

5. Yoshihara $\mathrm{H}$, Yoneoka, et al. National trends in spinal fusion for pediatric patients with idiopathic scoliosis: demographics, blood transfusions, and inhospital outcomes. Spine (Phila Pa 1976). 2014;39(14):1144-50.

6. Hany A, Gawwad, et al. Predicting lowest hemoglobin level and risk of blood transfusion in spinal fusion surgery for adolescent idiopathic scoliosis. Eur Spine J. 2019;28(6):1342-8.

7. Mange TR, Sucato DJ, Poppino KF, et al. The incidence and risk factors for perioperative allogeneic blood transfusion in primary idiopathic scoliosis surgery. Spine Deform. 2020. https://doi.org/10.1007/s43390-020-00093-6.

8. Minhas SV, Chow I, Bosco J, et al. Assessing the rates, predictors, and complications of blood transfusion volume in posterior arthrodesis for adolescent idiopathic scoliosis. Spine (Phila Pa 1976). 2015;40(18):1422.

9. Hassan $\mathrm{N}$, Halanski M, Wincek J, et al. Blood management in pediatric spinal deformity surgery: review of a 2-year experience. Transfusion. 2011;51(10): 2133-41.

10. Kwan MK, Chan CY. Does a dual attending surgeon strategy confer additional benefit for posterior selective thoracic fusion in Lenke 1 and 2 adolescent idiopathic scoliosis (AIS)? A prospective propensity matching score analysis. Spine J. 2017;17(2):224-9.

11. Chan CY, Kwan MK. Perioperative outcome in posterior spinal fusion for adolescent idiopathic scoliosis: a prospective study comparing single versus two attending surgeons strategy. Spine (Phila Pa 1976). 2016;41(11):E694-9.

12. Dupuis C, Michelet D, Hilly J, et al. Predictive factors for homologous transfusion during paediatric scoliosis surgery. Anaesth Crit Care Pain Med. 2015;34(6):327-32.

13. Yu X, Xiao H, Wang R, et al. Prediction of massive blood loss in scoliosis surgery from preoperative variables. Spine (Phila Pa 1976). 2013;38(4):350-5.

14. Yao Z, Li H, Zhang $X$, et al. Incidence and risk factors for instrumentationrelated complications after scoliosis surgery in pediatric patients with NF-1. Spine (Phila Pa 1976). 2018;43(24):1719-24.

15. Li Y, Luo M, Wang W, et al. A computed tomography-based comparison of abnormal vertebrae pedicles between dystrophic and nondystrophic scoliosis in neurofibromatosis type 1. World Neurosurg. 2017;106:898-904.

16. Chang DG, Yang JH, Lee JH, et al. Congenital scoliosis treated with posterior vertebral column resection in patients younger than 18 years: longer than 10-year follow-up. J Neurosurg Spine. 2016;25(2):225-33.

\section{Publisher's Note}

Springer Nature remains neutral with regard to jurisdictional claims in published maps and institutional affiliations.

Ready to submit your research? Choose BMC and benefit from:

- fast, convenient online submission

- thorough peer review by experienced researchers in your field

- rapid publication on acceptance

- support for research data, including large and complex data types

- gold Open Access which fosters wider collaboration and increased citations

- maximum visibility for your research: over $100 \mathrm{M}$ website views per year

At $\mathrm{BMC}$, research is always in progress.

Learn more biomedcentral.com/submissions 